\title{
Interleukin-20 targets podocytes and is upregulated in experimental murine diabetic nephropathy
}

\author{
Yu-Hsiang Hsu ${ }^{1,2,3}$, Hsing-Hui $\mathrm{Li}^{4}$, Junne-Ming Sung ${ }^{5}$, Wei-Yu Chen ${ }^{4}$, Ya-Chin $\mathrm{Hou}^{6}$, Yun-Han Weng ${ }^{4}$, \\ Wei-Ting Lai ${ }^{4}$, Chih-Hsing $\mathrm{Wu}^{7}$ and Ming-Shi Chang ${ }^{3,4}$
}

Interleukin (IL)-20, a proinflammatory cytokine of the IL-10 family, is involved in acute and chronic renal failure. The aim of this study was to elucidate the role of IL-20 during diabetic nephropathy development. We found that IL-20 and its receptor IL-20R1 were upregulated in the kidneys of mice and rats with STZ-induced diabetes. In vitro, IL-20 induced MMP-9, MCP-1, TGF- $\beta 1$ and VEGF expression in podocytes. IL-20 was upregulated by hydrogen peroxide, high-dose glucose and TGF- $\beta 1$. In addition, IL-20 induced apoptosis in podocytes by activating caspase-8. In STZ-induced early diabetic nephropathy, IL-20R1-deficient mice had lower blood glucose and serum BUN levels and a smaller glomerular area than did wild-type controls. Anti-IL-20 monoclonal antibody (7E) treatment reduced blood glucose and the glomerular area and improved renal functions in mice in the early stage of STZ-induced diabetic nephropathy. ELISA showed that the serum IL-20 level was higher in patients with diabetes mellitus than in healthy controls. The findings of this study suggest that IL-20 induces cell apoptosis of podocytes and plays a role in the pathogenesis of early diabetic nephropathy.

Experimental \& Molecular Medicine (2017) 49, e310; doi:10.1038/emm.2016.169; published online 31 March 2017

\section{INTRODUCTION}

Diabetic nephropathy is a serious and common complication of type 1 and type 2 diabetes; it leads to end-stage renal disease in up to $30 \%$ of persons with diabetes. Advanced diabetic nephropathy is characterized by the glomerulosclerotic demise of glomerular capillaries, tubulointerstitial degeneration and fibrosis associated with a precipitous decline in the glomerular filtration rate. ${ }^{1,2}$ After the onset of albuminuria, the progression of diabetic nephropathy is influenced by several factors, such as transforming growth factor (TGF)- $\beta 1$, angiotensin II and advanced glycated proteins, which promote glomerular and tubular fibrogenesis. ${ }^{3,4}$

Recent studies ${ }^{5}$ in rats with streptozotocin (STZ)-induced diabetes suggest that podocytes may detach from the glomerular basement membrane, which leads to a loss of podocytes into the urinary space. Apoptosis of resident glomerular podocytes has recently been proposed ${ }^{6,7}$ as a cellular mechanism underlying podocyte loss in nondiabetic glomerulopathy and experimental diabetic nephropathy. The generation of glucose-induced reactive oxygen species (ROS), which cause the apoptosis of podocytes and podocyte depletion, also suggests that podocyte apoptosis and depletion is an early mechanism that leads to diabetic nephropathy in mouse type 1 and type 2 diabetic models. ${ }^{7}$

The pleiotropic inflammatory cytokine IL-20, a member of the IL-10 family, 8,9 is expressed in monocytes, epithelial cells and endothelial cells. IL-20 affects multiple cell types by activating a heterodimer receptor complex: IL-20R1/IL-20R2 or IL-22R1/IL-20R2 ${ }^{10}$ Other studies ${ }^{11-15}$ have reported that IL-20 and its receptors (IL-20R1, IL-20R2 and IL-22R1) are all expressed on osteoclasts, osteoblasts, hepatocytes, rheumatoid synovial fibroblasts, proximal tubular epithelial cells, breast cancer cells, bladder cancer cells and oral cancer cells. IL-20 is involved in various inflammatory diseases, ${ }^{16}$ such as psoriasis, ${ }^{8,17,18}$ rheumatoid arthritis, ${ }^{12}$ atherosclerosis, ${ }^{16,19}$ ischemic stroke $^{20}$ and renal failure. ${ }^{13,21}$

We have previously ${ }^{13,21}$ reported that the involvement of IL-20 in renal failure mediates the apoptosis of renal epithelial cells and the induction of renal fibroblasts through TGF- $\beta 1$. Therefore, IL-20 is a local mediator during the

\footnotetext{
${ }^{1}$ Institute of Clinical Medicine, College of Medicine, National Cheng Kung University, Tainan, Taiwan; ${ }^{2}$ Research Center of Clinical Medicine, National Cheng Kung University Hospital, Tainan, Taiwan; ${ }^{3}$ Research Center of New Antibody Drug, National Cheng Kung University, Tainan, Taiwan; ${ }^{4}$ Department of Biochemistry and Molecular Biology, College of Medicine, National Cheng Kung University, Tainan, Taiwan; ${ }^{5}$ Department of Internal Medicine, National Cheng Kung University Hospital, Tainan, Taiwan; ${ }^{6}$ Institute of Basic Medical Sciences, College of Medicine, National Cheng Kung University, Tainan, Taiwan and ${ }^{7}$ Department of Family Medicine, National Cheng Kung University Hospital, Tainan, Taiwan

Correspondence: Professor M-S Chang, Department of Biochemistry and Molecular Biology, College of Medicine, National Cheng Kung University, Tainan 704, Taiwan.
}

E-mail: mschang@mail.ncku.edu.tw

Received 19 September 2016; accepted 12 October 2016 
progression of acute and chronic renal failure. However, the role of IL-20 in diabetic nephropathy and its function in podocytes are not well understood. In this study, we used a model of STZ-induced diabetes and analyzed the role of IL-20 in diabetic nephropathy.

\section{MATERIALS AND METHODS}

\section{Animal model of STZ-induced diabetes mellitus and treatments}

Male Wistar rats (300-350 g) were fasted for $6-8 \mathrm{~h}$ and then intraperitoneally injected with a single $70 \mathrm{mg} \mathrm{kg}^{-1}$ dose of STZ in sodium citrate buffer ( $\mathrm{pH} 4.5) .{ }^{22}$ Male C57BL/6 mice (20-25 g) were fasted for $4-6 \mathrm{~h}$ and then injected with a single high dose (200 $\mathrm{mg} \mathrm{kg}^{-1}$ of body weight) or multiple low doses $\left(40 \mathrm{mg} \mathrm{kg}^{-1}\right.$ of body weight per day for 8 consecutive days) of STZ in sodium citrate buffer. Rats and mice with blood glucose concentrations greater than $300 \mathrm{mg} \mathrm{dl}^{-1}$ were considered diabetic and used in the experiments. Control rats and mice were injected with sodium citrate buffer alone. In the single high-dose STZ-injected model, the mice were divided into three groups: no treatment (STZ, $n=13), 3 \mathrm{mg} \mathrm{kg}^{-1} 7 \mathrm{E}(n=13)$, and $3 \mathrm{mg} \mathrm{kg}^{-1}$ control antibody (mIgG; $n=13$ ) twice per week until the end of the experiment. In the multiple low-dose STZ-injected model, the mice were divided into three groups: no treatment (STZ, $n=9), 3 \mathrm{mg} \mathrm{kg}^{-1} 7 \mathrm{E}(n=9)$, and $3 \mathrm{mg} \mathrm{kg}^{-1}$ control antibody (mIgG; $n=9)$ twice per week for 16 weeks. The left kidneys were fixed in $3.7 \%$ formaldehyde for immunohistochemical staining, and the right kidneys were stored in liquid nitrogen for RNA isolation. All animal experiments were conducted according to protocols based on the Taiwan National Institutes of Health (Taipei, Taiwan) standards and guidelines for the care and use of experimental animals. The research procedures were approved by the Animal Ethics Committee of National Cheng Kung University. The methods were performed in accordance with the approved guidelines. All efforts were made to minimize animal suffering and to reduce the number of animals used.

\section{Reagents}

STZ and NAC ( $N$-acetyl-L-cysteine) were purchased from SigmaAldrich Chemical Co. (St. Louis, MO, USA). The mouse (m) IL-20 recombinant protein was expressed in E. coli. A cDNA-clone encoding the mIL-20 sequence from leucine to leucine (aa 25-176) was inserted into the prokaryotic expression vector pET43a (Novagen, Madison, WI, USA). A tag consisting of six histidine residues was placed at the $\mathrm{C}$ terminus of the recombinant proteins. The protein was found mostly in the cytosol and, using affinity chromatography, was purified to more than $95 \%$.

\section{Determination of blood glucose}

Blood glucose levels in blood samples collected from tail veins were assessed using One Touch Ultra meters and test strips purchased from Johnson \& Johnson Company (Milpitas, CA, USA).

\section{Real-time quantitative polymerase chain reaction}

To analyze the expression of IL-20 and its receptors in the kidneys of mice and rats with STZ-induced diabetes, total RNA was extracted using TRIzol reagent (Invitrogen, Carlsbad, CA, USA), and then total RNA underwent reverse transcription (Clontech, Palo Alto, CA, USA) according to the manufacturer's instructions. The amplified template was detected using SYBR Green with a real-time PCR system
(LightCycler 480 System; Roche, Indianapolis, IN, USA) using gene-specific primers. Glyceraldehyde phosphate dehydrogenase (GAPDH) was used as an internal control. To examine the expression of MMP-9, MCP-1, TGF- $\beta 1$ and VEGF, mouse podocytes were incubated with mIL-20 $\left(200 \mathrm{ng} \mathrm{ml}^{-1}\right)$ for $4-8 \mathrm{~h}$. To examine the expression of IL-20, mouse podocytes were treated with hydrogen peroxide $(0.5 \mathrm{~mm})$, glucose $(25 \mathrm{~mm})$ and TGF- $\beta 1\left(20 \mathrm{ng} \mathrm{ml}^{-1}\right)$ for 3-8 h. NAC, a potent free-radical scavenger, was used to inhibit ROS-induced apoptosis. To test whether NAC affects $\mathrm{H}_{2} \mathrm{O}_{2}$-induced IL-20 expression in podocytes, mouse podocytes were preincubated with 5-20 mM of NAC for $1 \mathrm{~h}$ and then treated with $\mathrm{H}_{2} \mathrm{O}_{2}$ for another $8 \mathrm{~h}$. Real-time PCR data were analyzed using the comparative threshold cycle (Ct) method according to the manufacturer's instructions. The forward and reverse primers are listed below $(\mathrm{F}=$ forward primer, $\mathrm{R}=$ reverse primer, $\mathrm{r}=$ primer for rat genes and $\mathrm{m}=$ primer for mouse genes):

rIL-20-F: 5'-ATGAGAGGCTTTCGTCTTGC-3'

rIL-20-R: 5'-TAACATCTGCTTCATCCATCT-3'

rIL-20R1-F: 5'-TTCTCTGCGATTGGCTACTCA-3'

rIL-20R1-R: 5'-TACGCTGACCTCATCACTGC-3'

rGAPDH-F: 5'-ACATGCCGCCTGGAGAAACCT- $3^{\prime}$

rGAPDH-R: 5' ${ }^{\prime}$-TCCACCACCCTGTTGCTGTAG-3' mTGF- $\beta 1$-F: 5'-CGGCAGCTGTACATTGACTT-3' mTGF- $\beta 1-R$ : $5^{\prime}$-TCAGCTGCACTTGCAGGAG-3' mMMP-9-F: 5'-ACATCTTCGACGCCATCGCG-3' mMMP-9-R: 5'-AACTCACGCGCCAGTAGAAG-3' mMCP-1-F: 5'-AGGTCCCTGTCATGCTTCTG-3' mMCP-1-R: 5'-GCTGCTGGTGATCCTCTTGT-3' mVEGF-F: $5^{\prime}$-GCGTGCCCACGTCAGAGAGC-3' mVEGF-R: 5'-GGCTCACCGCCTTGGCTTGT-3' mIL-20-F: 5'-AGGACGACTGAGTCTTTGAAA-3' mIL-20-R: 5'-CATTGCTTCTTCCCCACAATG-3' mGAPDH-F: $5^{\prime}$-GATGGGTGTGAACCACGAGA- ${ }^{\prime}$ mGAPDH-R: 5'-CAGATCCACGACGGACACAT-3'

\section{Immunohistochemical staining}

Anti-hIL-20 monoclonal antibody (mAb) 7E was prepared and purified as previously described. ${ }^{18}$ Incubation of the paraffin tissue sections with the mouse IgG1 isotype (clone 11711; R\&D Systems, Minneapolis, MN, USA) instead of primary Ab served as the negative control. We used $3 \mu \mathrm{g} \mathrm{ml}^{-1}$ as the working concentration for each primary $\mathrm{Ab}$ and for the control mouse IgG1. Immunoreactivity was detected using the 3-amino-9-ethylcarbazole (AEC) substrate kit for peroxidase (DakoCytomation, Carpinteria, CA, USA), and nuclei were counterstained with hematoxylin. For apoptotic cell staining, mouse podocytes were incubated with mIL-20 $\left(200 \mathrm{ng} \mathrm{ml}^{-1}\right)$ or glucose $(25 \mathrm{~mm})$ for $24 \mathrm{~h}$. After the culture medium had been removed, the cells were washed three times with cold phosphatebuffered saline. The cells were stained with TUNEL (terminal deoxynucleotidyl transferase-mediated dUTP nick-end labeling) agent (Promega, Madison, WI, USA) and DAPI according to the manufacturer's instructions.

\section{Immunofluorescence}

The localization of IL-20 was assessed by immunofluorescent staining of endogenous IL-20 and co-staining with a specific marker for podocytes. The $7 \mathrm{E}$ was pre-conjugated to biotin according to the manufacturer's instructions (Biotin type 1 antibody conjugation kit; Bio-Rad AbD Serotec, Kidlington, UK). Paraffin-embedded tissue samples were prepared for immunofluorescent staining with biotin- 
conjugated $7 \mathrm{E}$ at $4{ }^{\circ} \mathrm{C}$ overnight. The next day, the tissue samples were incubated for $2 \mathrm{~h}$ with FITC-conjugated streptavidin (eBioscience, San Diego, CA, USA). The samples were then incubated for $4 \mathrm{~h}$ with nephrin antibody (AnaSpec Inc., San Jose, CA, USA), then for $2 \mathrm{~h}$ with Alexa Fluor 594-conjugated anti-rabbit secondary antibody (Invitrogen), and finally mounted on slides with Vectashield Mounting Medium containing DAPI (Vector Laboratories, Peterborough, UK).

\section{Cell culture}

Conditional immortalized mouse podocytes, which were kindly provided by Peter Mundel, MD (University of Miami Leonard M. Miller School of Medicine, Miami, FL, USA), were cultured as previously described. ${ }^{23}$ Briefly, the cells were first grown under permissive conditions $\left(33^{\circ} \mathrm{C}\right)$ in RPMI-1640 containing $10 \%$ fetal bovine serum, $10 \mathrm{U} \mathrm{ml}^{-1}$ of interferon (IFN)- $\gamma$ and $100 \mathrm{U} \mathrm{ml}^{-1}$ of penicillin/streptomycin in type I collagen-coated flasks. The cells were cultured for 14 days under non-permissive conditions $\left(37^{\circ} \mathrm{C}\right)$ in serum-containing medium without IFN- $\gamma$. All in vitro experiments were performed using mouse podocytes between passages 15 and 23.

\section{Immunocytochemical staining}

Immunocytochemical staining was conducted as previously described. ${ }^{12}$ Briefly, mouse podocytes were grown on $15-\mathrm{cm}$ dishes, circled using a pap-pen, fixed and blocked, and then primary antibodies were added. Anti-IL-20 mAb 7E, anti-IL-20R1 mAb, anti-IL-20R2 polyclonal $\mathrm{Ab}$ and anti-IL-22R1 mAb (R\&D Systems) were used for staining according to the manufacturer's instructions. After the podocytes had been incubated with secondary antibodies, their immunoreactivity was detected using an AEC substrate kit for peroxidase, and the nuclei were counterstained with hematoxylin.

\section{Detection of cell death}

The mouse podocytes were incubated with mIL-20 (100, 200, $\left.400 \mathrm{ng} \mathrm{ml}^{-1}\right)$ or glucose $(25 \mathrm{~mm})$ for $72 \mathrm{~h}$. After the culture medium had been removed, the cells were trypsinized and fixed with $50 \%$ ethanol. The cells were washed three times with cold phosphate-buffered saline, stained with propidium iodide (PI) for $10 \mathrm{~min}$ and then analyzed by flow cytometry. The presence of the sub-G0/G1 phase was used as an indicator of cell death. The percentage of cells in sub-G0/G1 phase was quantitated using WinMDI 2.8 software (The Scripps Research Institute, La Jolla, CA, USA).

\section{Western blotting}

Mouse podocytes were cultured in $15-\mathrm{cm}$ dishes and starved for $24 \mathrm{~h}$. The cells were then stimulated with mIL-20 $\left(400 \mathrm{ng} \mathrm{ml}^{-1}\right)$ for $24 \mathrm{~h}$, and the cell lysate was isolated. Western blotting with anti-caspase- 8 and anti-caspase- 9 antibodies (Cell Signaling Technology, Inc., Danvers, MA, USA) was performed to analyze the cell lysate according to the manufacturer's instructions. For signal transduction analysis, mouse podocytes were starved for $24 \mathrm{~h}$ and then stimulated with mIL-20 $\left(200 \mathrm{ng} \mathrm{ml}^{-1}\right)$ for the indicated times. Western blotting with antibodies specific for $\beta$-actin, phosphorylated p38, JNK and ERK (Cell Signaling Technology) was conducted according to the manufacturer's instructions.

\section{Analysis of the glomerular area}

Fifty digital images of the glomerular area were collected from each kidney section and then analyzed (Image J software; http://rsb. info.nih.gov/ij/index.html). ${ }^{24}$

\section{Patients and controls}

From National Cheng Kung University Hospital, we enrolled 46 healthy volunteers and 78 patients with diabetes mellitus. Signed informed consent was obtained from all participants. Patients with diabetes mellitus were defined as having a blood glucose level higher than $126 \mathrm{mg} \mathrm{dl}^{-1}$ before meals and an HbAlc (glycosylated hemoglobin) value higher than 6.5\%. The study was approved by the Human Research Review Committee of the National Cheng Kung University Medical Center and was in accord with the Declaration of Helsinki guidelines. Blood samples were collected and serum was prepared by nurses according to the standard procedures. Blood was centrifuged (2000 r.p.m. for $10 \mathrm{~min}$ at $4{ }^{\circ} \mathrm{C}$ ), and serum was collected. All samples were stored at $-80^{\circ} \mathrm{C}$ until used. Levels of IL-20 in the serum of the participants were determined using a human IL-20 ELISA kit (PeproTech, Rocky Hill, NJ, USA) according to the manufacturer's instructions.

\section{Statistical analysis}

Prism 6.0 (GraphPad Software, San Diego, CA, USA) was used for the statistical analysis. A one-way analysis of variance nonparametric Kruskal-Wallis test was used to compare the data between groups. Post hoc comparisons were performed using Dunn's multiple comparison test. The threshold for significance was set at $P<0.05$.

\section{RESULTS}

\section{IL-20 and IL-20R1 were upregulated in the kidneys of mice with STZ-induced diabetes}

We used a mouse model of STZ-induced diabetes ${ }^{22}$ to examine whether IL-20 is involved in diabetic nephropathy. The blood glucose of the mice was analyzed from 2 to 8 weeks after they had been injected with STZ. The blood glucose levels in STZ-treated mice were significantly higher than those in control mice (Figure 1a). To analyze whether IL-20 is involved in the pathogenesis of diabetic nephropathy, we measured the expression levels of IL-20 and its receptors (IL-20R1, IL-20R2 and IL-22R1) at different time points in STZ-induced diabetic mice. Real-time quantitative polymerase chain reaction (RT-qPCR) showed that the transcripts of IL-20 and IL-20R1 were upregulated in the kidneys of diabetic mice, whereas the IL-20R2 and IL-22R1 transcripts were not altered (Figure 1b). ELISA showed that the levels of IL-20 protein were significantly increased in kidney tissues from 4 to 8 weeks after STZ treatment (Figure 1c). Moreover, a rat model of STZ-induced diabetes was used to confirm the role of IL-20 in diabetic nephropathy with similar results (Supplementary Figure S1A-D).

\section{High expression levels of IL-20 in renal podocytes of mice with STZ-induced diabetes}

To clarify which cells express IL-20 in the kidney of STZ-induced diabetic mice, we used immunohistochemical staining with anti-IL-20 mAb and observed strong staining of IL-20 in podocytes (Figure 1d). In contrast, little IL-20 


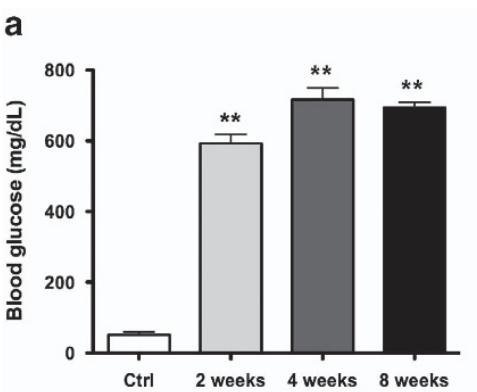

c

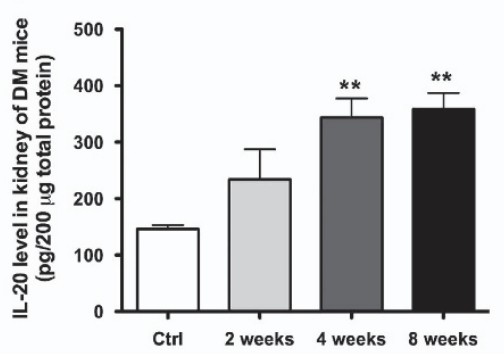

d Healthy mice

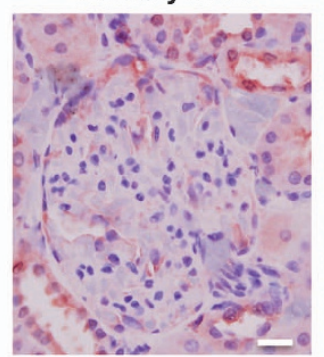

b

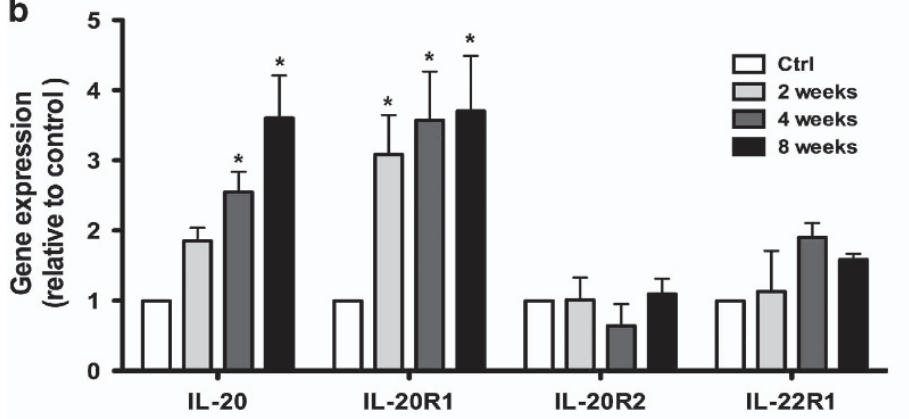

e
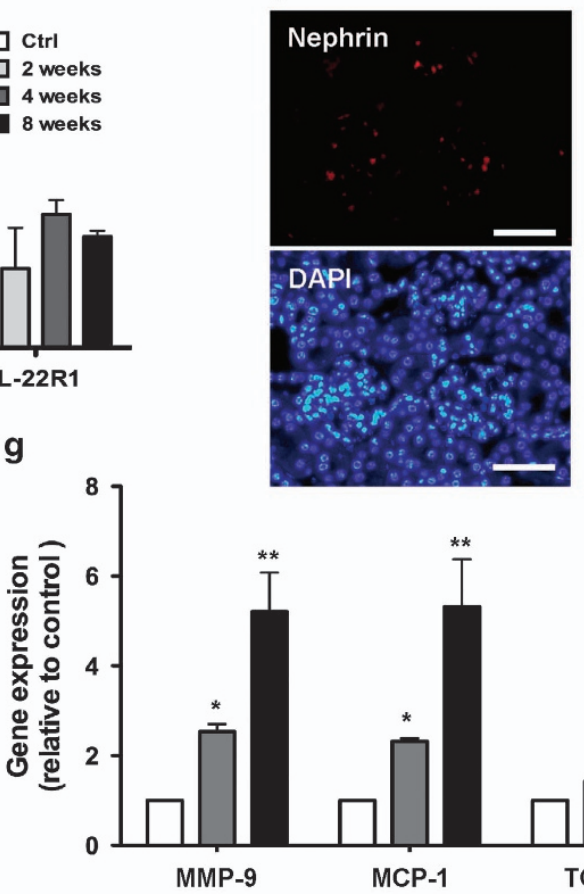

g
Anti-IL-20R1

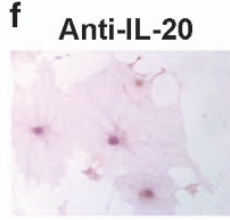

Anti-IL-22R1
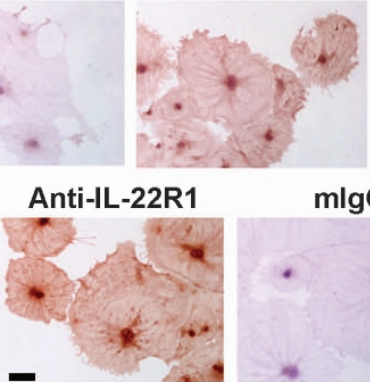

Anti-IL-20R2
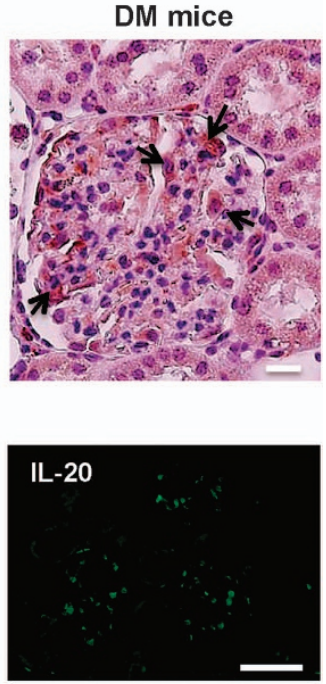

Merge

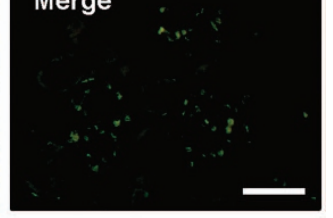

mlgG
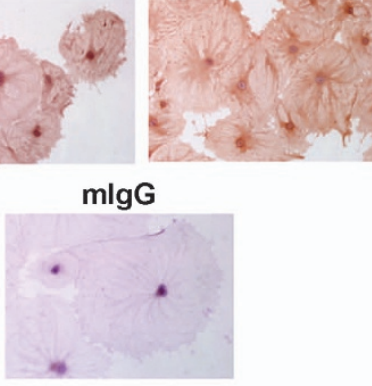

Figure $1 \mathrm{IL}-20$ was upregulated in the renal podocytes of mice with STZ-induced early diabetic nephropathy and induced fibrogenic gene expression. (a-e) Mice ( $n=3$ per group) were killed at the indicated times after STZ injection. Control mice were killed 8 weeks after they had been injected with buffer. (a) The blood glucose levels of mice treated with or without STZ were analyzed. ${ }^{* *} P<0.01$ compared with controls. The data are expressed as the mean \pm s.d. of three independent experiments, each performed in triplicate. (b) Renal tissues from mice with STZ-induced diabetic nephropathy were collected, mRNA was isolated, and the transcripts of IL-20, IL-20R1, IL-20R2 and IL-22R1 were measured by RT-qPCR. GAPDH served as an internal control. ${ }^{*} P<0.05$, compared with the controls. The data are expressed as the mean \pm s.d. of three independent experiments, each performed in triplicate. (c) Levels of IL-20 in kidney from control mice and mice injected with STZ were measured by ELISA ( $n=3$ per group). Control mice were killed 8 weeks after they had been injected with buffer. ${ }^{* *} P<0.01$ compared with the controls. The data are expressed as the mean \pm s.d. of three independent experiments, each performed in triplicate. (d) Mice were killed 8 weeks after STZ treatment. Paraffin sections of kidney tissue were stained with anti-IL-20 mAb 7E. The reaction was detected using AEC chromogen stain (red), and the nuclei were counterstained with hematoxylin (blue). IL-20 stained strongly in podocytes (arrows). The figures represent similar patterns in three individual mice. Magnification: $\times 200$. Scale bars, $5 \mu \mathrm{m}$. (e) Paraffin sections of kidney tissue were stained with 7E (green) and nephrin antibody as a marker of podocytes (red). Nuclei were stained with DAPI (blue). The figures represent similar patterns in three individual mice. Magnification: $\times 200$. Scale bars, $25 \mu \mathrm{m}$. (f) Mouse podocytes were stained to evaluate IL-20, IL-20R1, IL-20R2 and IL-22R1 expression using the indicated monoclonal antibodies. Mouse (m) IgG served as a negative control. The reaction was detected using AEC chromogen stain (red), and the nuclei were counterstained with hematoxylin (blue). The data are representative of two independent experiments. Magnification: $\times 200$. Scale bars, $100 \mu \mathrm{m}$. (g) Mouse podocytes were treated with or without IL-20 (200 $\mathrm{ng} \mathrm{ml}^{-1}$ ) for the indicated times. Total RNA was isolated for RT-qPCR analysis with primers specific for MMP-9, MCP-1, TGF- $\beta 1$ and VEGF to amplify the transcripts. GAPDH was an input control. ${ }^{*} P<0.05,{ }^{*} P<0.01$ compared with untreated controls. The data are expressed as the mean \pm s.e.m. of three independent experiments, each performed in triplicate. 
was detected in podocytes in the kidneys of control mice. Immunofluorescent staining also revealed costaining of IL-20 and nephrin (a podocyte marker) (Figure 1e), which confirmed that IL-20 was highly expressed in renal podocytes of diabetic mice. Similar results were obtained in the STZ-induced diabetic rat model (Supplementary Figure S1E and F).

\section{Mouse podocytes expressed endogenous IL-20 receptors in vitro}

We hypothesized that IL-20 targets podocytes, potentially inducing inflammatory responses in the pathogenesis of diabetic nephropathy. In our in vitro study, we used a conditionally immortalized mouse podocyte cell line. ${ }^{23}$ IHC staining showed that all three IL-20 receptor subunits (IL-20R1, IL-20R2 and IL-22R1), but not IL-20, were endogenously expressed in healthy podocytes (Figure 1f), confirming our hypothesis.

\section{IL-20 upregulated MMP-9, MCP-1, TGF- $\beta 1$ and VEGF expression in mouse podocytes}

The progression of diabetic nephropathy is manifested by gradual scarring of both the renal glomerulus and the tubulointerstitial region. ${ }^{25}$ Many molecules that are correlated with diabetes mellitus, namely, MMP-9, MCP-1, TGF- $\beta 1$, TGF- $\beta$ R2, VEGF, IL-6, angiotensinogen, angiotensin II receptors and MMP-2, are involved in driving fibrogenesis. We analyzed the effects of IL-20 on the production of these molecules in mouse podocytes. Mouse podocytes were incubated with IL-20, and gene expression was analyzed using RT-qPCR. The expression levels of MMP-9, MCP-1, TGF- $\beta 1$ and VEGF (Figure 1g) were upregulated in IL-20-treated podocytes, but the transcripts of IL-6, angiotensinogen, angiotensin II receptors, TGF- $\beta$ R2 and MMP- 2 were not altered (data not shown).

\section{Hydrogen peroxide, glucose and TGF- $\beta 1$ induced IL-20 expression in mouse podocytes}

Other studies have reported that glucose, ROS and TGF- $\beta 1$ can activate podocytes. ${ }^{3,7}$ Therefore, we examined whether IL-20 expression could be induced in mouse podocytes in the presence of these stimuli. RT-qPCR showed that hydrogen peroxide markedly upregulated the IL-20 transcripts in podocytes (Figure 2a). In addition, IL-20 expression was also significantly upregulated in podocytes after glucose and TGF- $\beta 1$ treatment (Figure $2 \mathrm{~b}$ and $\mathrm{c}$ ). NAC ( $N$-acetyl-Lcysteine) is a potent free-radical scavenger that is known to inhibit ROS-induced apoptosis. To assess whether NAC affects $\mathrm{H}_{2} \mathrm{O}_{2}$-induced IL-20 expression in podocytes, mouse podocytes were preincubated with 5-20 mM of NAC for $1 \mathrm{~h}$ and then treated with $\mathrm{H}_{2} \mathrm{O}_{2}$ for another $8 \mathrm{~h}$. RT-qPCR showed that NAC dose-dependently inhibited $\mathrm{H}_{2} \mathrm{O}_{2}$-induced IL-20 expression in podocytes (Supplementary Figure S2).

\section{IL-20 dose-dependently induced apoptosis in mouse podocytes} Podocyte apoptosis and depletion are critical steps in the pathogenesis of diabetic nephropathy. To examine whether
IL-20 induced cell apoptosis in podocytes, we incubated podocytes with different concentrations of IL- 20 for $72 \mathrm{~h}$ and then analyzed the percentage of cell death by flow cytometry with PI staining. Cells treated with a high dose of glucose served as positive controls. FASC analysis showed that IL-20 dose-dependently induced cell death in podocytes (Figure 2d). TUNEL analysis revealed cells treated with IL-20 or a high dose of glucose (positive control) for $24 \mathrm{~h}$ that were stained with the TUNEL agent. Only a small number of apoptotic cells was detected in the untreated control group, whereas a large number was detected in podocytes treated with IL-20 (Figure 2e). There are two major apoptotic pathways in the pathogenesis of diabetic nephropathy: the intrinsic and extrinsic pathways. To clarify the apoptosis pathway induced by IL-20, we performed western blotting with anticaspase- 8 and -9 antibodies. We found that IL-20 activated caspase-8, but not caspase-9 (data not shown), in podocytes, which indicated that IL-20 caused apoptosis through the extrinsic pathway (Figure 2f).

\section{IL-20 activated ERK, JNK and p38 in mouse podocytes}

To evaluate the downstream signals induced by IL-20, mouse podocytes were treated with IL-20, and cell lysates were analyzed by western blotting with antibodies against phosphorylated p38, JNK, and ERK. The phosphorylation of p38, JNK and ERK was higher in IL-20-treated mouse podocytes, and maximal phosphorylation occurred $10 \mathrm{~min}$ after treatment (Figure 2g).

\section{An IL-20R1 deficiency reduced the severity of STZ-induced} diabetic nephropathy

IL-20R1 was upregulated in the kidneys of mice with STZ-induced diabetes (Figure 1c), which suggested that IL-20R1 might be important for IL-20-mediated inflammatory responses and might be involved in the pathogenesis of diabetic nephropathy. Therefore, we investigated the effect of an IL-20R1 deficiency on IL-20-mediated early diabetic nephropathy. To confirm the in vivo role of IL-20 in diabetic nephropathy, we used the STZ-induced diabetic model to investigate whether IL-20R1 receptor signaling was important for controlling disease processes. STZ-induced diabetes resulted in higher blood glucose levels, higher serum BUN levels, and an enlarged glomerulus. Blood glucose was significantly $(P<0.05)$ lower in STZ-IL-20R1 ${ }^{-/-}$mice than in STZ-IL-20R1+/+ mice (Figure 3a). The STZ-IL-20R1 ${ }^{-/-}$mice had a longer survival rate than the STZ-IL-20R1+/+ mice (Figure 3b). The serum BUN levels in STZ-IL-20R1 ${ }^{-/-}$mice were lower than those in STZ-IL-20R1+/+ mice (Figure 3c). Glomerular enlargement during diabetes is an indication of renal damage. Thus, we measured the average glomerular area of the cross-section. The average glomerular area was lower in STZ-IL-20R1 $1^{-/-}$mice than in the STZ-IL-20R1+/+ controls (Figure 3d) on day 49 after STZ induction. 

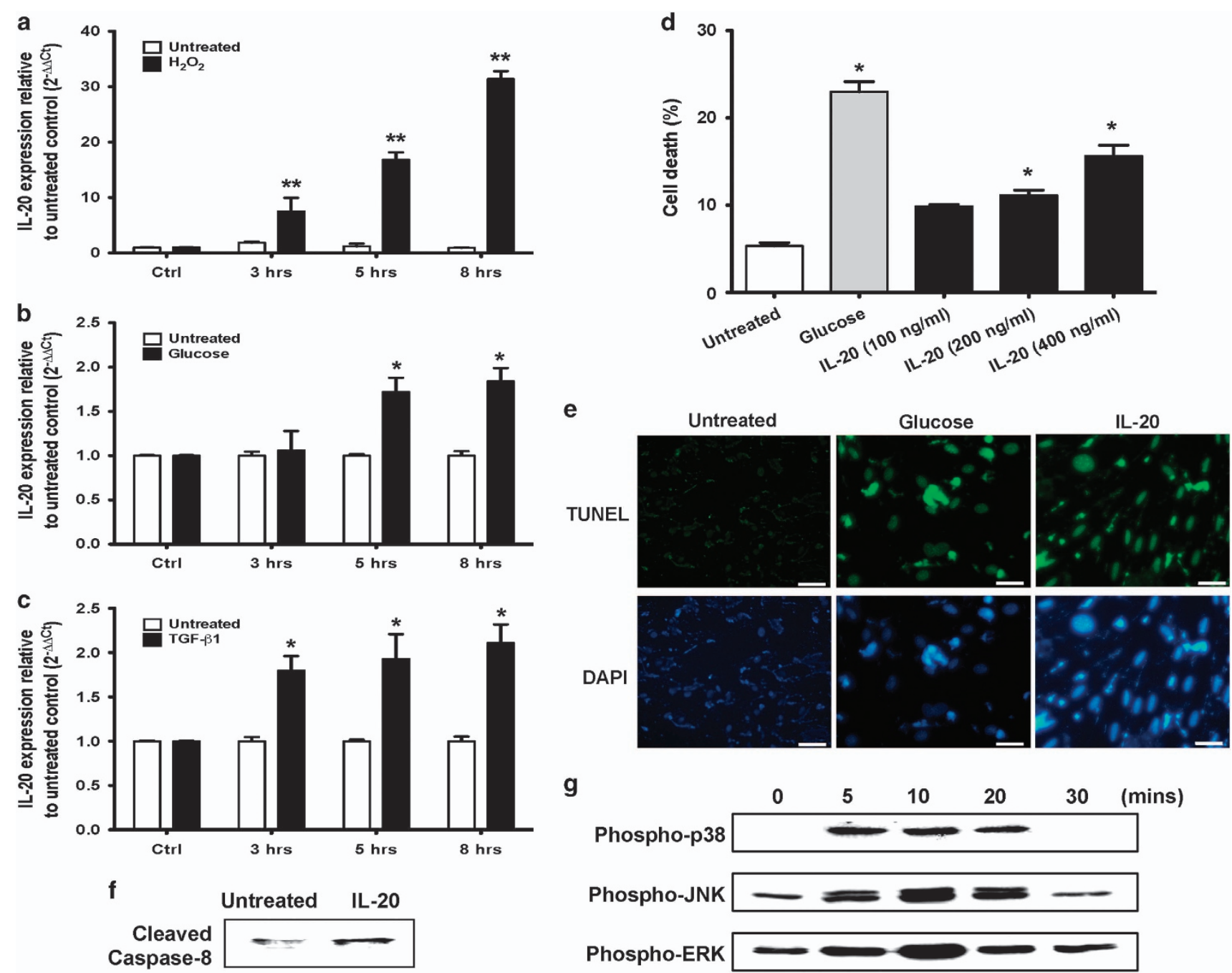

DAPI
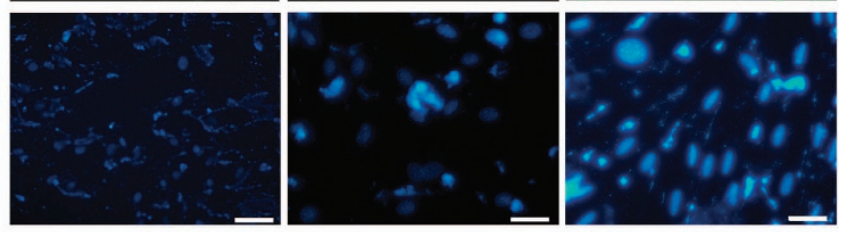

g
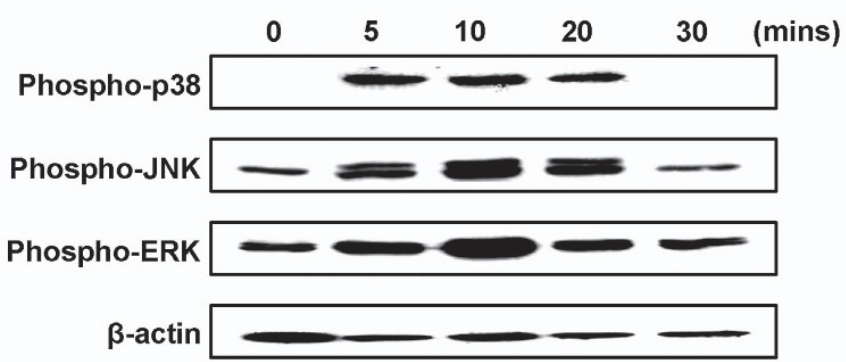

Figure 2 Functions of IL-20 in mouse podocytes. (a-c) Mouse podocytes were treated with hydrogen peroxide $(0.5 \mathrm{~mm})$, glucose $(25 \mathrm{~mm})$ and TGF- $\beta 1\left(20 \mathrm{ng} \mathrm{ml}^{-1}\right)$ for the indicated times. Total RNA was isolated for RT-qPCR using primers specific for IL-20 to amplify the transcripts. GAPDH served as an input control. ${ }^{*} P<0.05,{ }^{*} P<0.01$ compared with the untreated controls. The data are expressed as the mean \pm s.e.m. of three independent experiments, each performed in triplicate. (d) Mouse podocytes were treated with IL-20 (100, 200 or $400 \mathrm{ng} \mathrm{ml}^{-1}$ ) and glucose $(25 \mathrm{~mm})$ for $72 \mathrm{~h}$. The cells were fixed with ethanol, stained with propidium iodide (PI) and analyzed by flow cytometry. The percentages of dead cells (M1 region) are shown. ${ }^{*} P<0.05$ compared with the untreated controls. The data are expressed as the mean \pm s.e.m. of three independent experiments, each performed in triplicate. (e) Mouse podocytes were treated with glucose $(25 \mathrm{~mm})$ and $\mathrm{IL}-20\left(200 \mathrm{ng} \mathrm{ml}^{-1}\right)$ for $24 \mathrm{~h}$. The cells were stained with the TUNEL agent. The data are representative of three independent experiments. Magnification: $\times 200$. Scale bars, $30 \mu \mathrm{m}$. (f) Mouse podocytes were starved in serum-free medium for $24 \mathrm{~h}$ and then incubated with IL-20 (400 $\left.\mathrm{ng} \mathrm{ml}^{-1}\right)$ for $24 \mathrm{~h}$. Total cell lysates were analyzed by western blotting with specific antibodies against caspase- 8 and $\beta$-actin. The data are representative of three independent experiments. (g) Mouse podocytes were starved in serum-free medium for $24 \mathrm{~h}$ and then incubated with $\mathrm{mIL}-20\left(200 \mathrm{ng} \mathrm{ml}^{-1}\right)$ for the indicated time periods. Total cell lysates were analyzed by western blotting with specific antibodies against phospho-p38, JNK, ERK and $\beta$-actin. The data are representative of three independent experiments.

7E reduced the severity in single high-dose STZ-induced early diabetic nephropathy

On the basis of our in vitro results, we further investigated the effects of the anti-IL-20 mAb 7E in our mouse model of diabetic nephropathy. Blood glucose levels were determined in the mice after receiving control buffer $(n=8)$ or
STZ injection $(n=13)$, followed by no treatment (STZ, $n=13), 3 \mathrm{mg} \mathrm{kg}^{-1} 7 \mathrm{E}(n=13)$, or $3 \mathrm{mg} \mathrm{kg}^{-1}$ control antibody (mIgG; $n=13$ ) twice per week until the end of the experiment. Blood glucose was significantly reduced in the 7E-treated group compared with the mIgG-treated group at 8-22 days after STZ treatment (Figure 4a and b). The urine albumin/ 

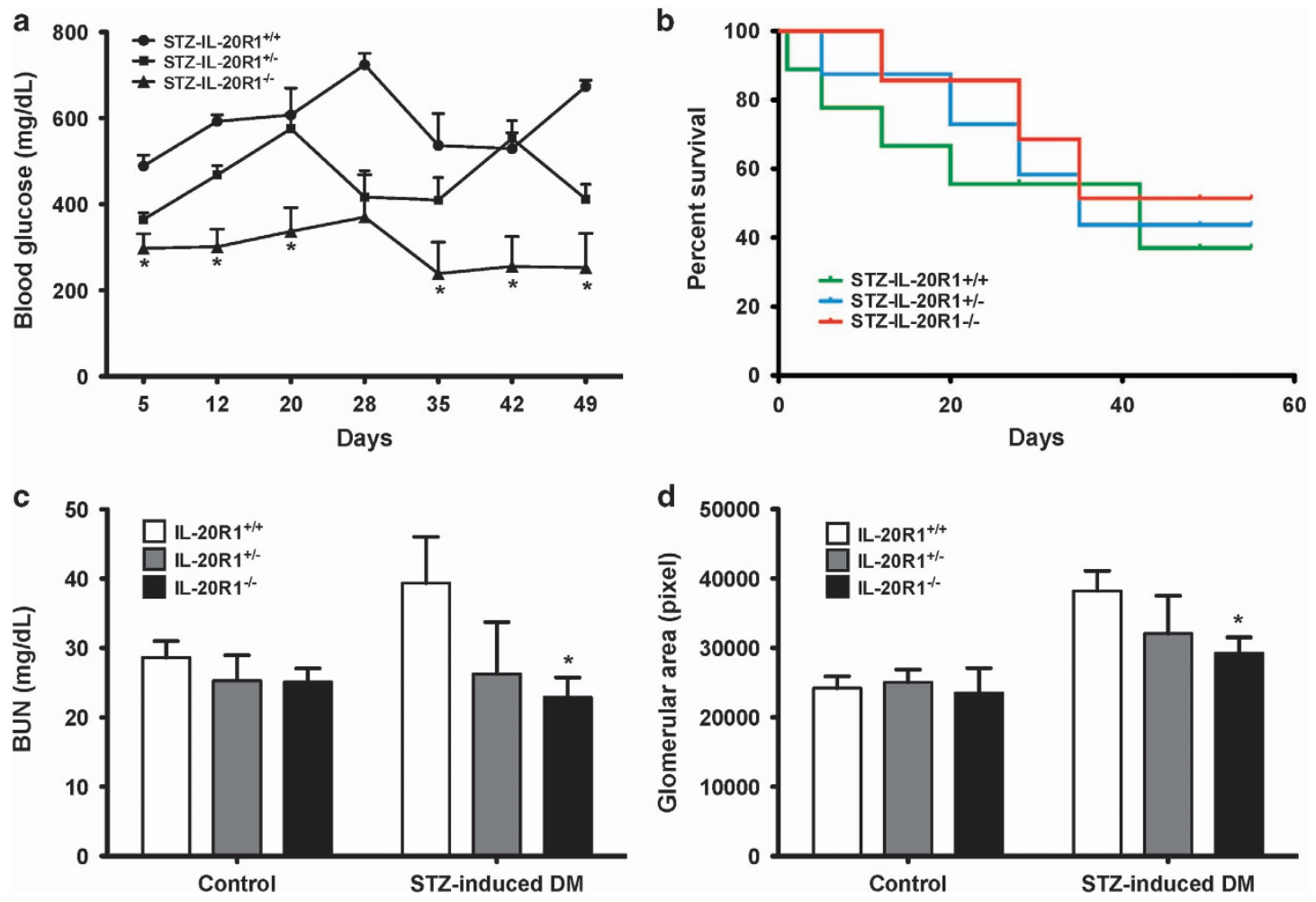

Figure 3 An IL-20R1 deficiency reduced the severity of STZ-induced diabetic nephropathy. (a) Blood glucose measurements in IL-20R $1^{+/+}$, IL-20R $1^{+/-}$and IL-20R $1^{-/-}$mice from day 5 to 49 after STZ treatment ( $n=8$ per group). ${ }^{*} P<0.05$ compared with IL-20R $1^{+/+}$ mice. The data are expressed as the mean \pm s.e.m. of three independent experiments. (b) Survival in each group ( $n=8$ per group) was monitored daily until the end of the experiment. The data are representative of three independent experiments. (c, d) Serum BUN levels and renal glomerular areas on day 49 were analyzed in IL-20R $1^{+/+}$, IL-20R $1^{+/-}$, and IL-20R $1^{-/-}$mice after STZ or control buffer treatment ( $n=8$ per group). ${ }^{*} P<0.05$ compared with $\mathrm{IL}-20 \mathrm{R} 1^{+/+}$mice. The data are expressed as the mean \pm s.e.m. of three independent experiments.

creatinine ratio was higher in the STZ-induced diabetes group than in the control group. Although 7E treatment decreased urine albumin/creatinine ratio, when the data were analyzed by one-way analysis of variance, they showed no significant difference (Figure 4c). In addition, more 7E-treated than mIgG-treated mice survived for the first 15 days after STZ treatment (Figure 4d). H\&E staining showed that STZ-induced renal injury was reduced in the 7E-treated group compared with the mIgG-treated group (Figure 4e). The average glomerular area was smaller in 7E-treated mice than in mIgG-treated mice at 21 days after STZ treatment (Figure 4f).

\section{E ameliorated renal dysfunction in multiple low-dose STZ-induced diabetic nephropathy}

To reduce nonspecific nephrotoxicity of STZ, we further investigated the effects of anti-IL-20 mAb 7E in the mouse model of multiple low-dose STZ-induced diabetic nephropathy. Mice with blood glucose concentrations greater than $300 \mathrm{mg} \mathrm{dl}^{-1}$ were considered diabetic and used in the experiments. The mice were divided into three groups: no treatment (STZ, $n=9), 3 \mathrm{mg} \mathrm{kg}^{-1} 7 \mathrm{E}(n=9)$, and $3 \mathrm{mg} \mathrm{kg}^{-1}$ control antibody $(\mathrm{mIgG})(n=9)$ twice per week for 16 weeks. Control mice received an injection of sodium citrate buffer alone.
Blood glucose was significantly reduced in the 7E-treated group compared with the mIgG-treated group at 10-16 weeks after antibody treatment (Figure 5a). The urine albumin/ creatinine ratio was higher in the mIgG-treated group than in the control group. The 7E treatment significantly decreased urine albumin/creatinine ratio compared with the mIgG-treated group at 16 weeks after antibody treatment (Figure 5b). Diabetic nephropathy is characterized by mesangial cell expansion and an accumulation of extracellular matrix proteins. We found that the percentage of mesangial cell expansion in renal tissue was significantly reduced after $7 \mathrm{E}$ treatment compared with the mIgG-treated group (Figure $5 c$ and $d$ ). Renal tissue from each group was then isolated for RNA extraction. RT-qPCR showed that iNOS, TNF- $\alpha$ and MCP-1 expression in the 7E-treated group were significantly lower than those in the mIgG-treated control group (Figure $5 \mathrm{e}-\mathrm{g}$ ). These data support our hypothesis that inhibition of IL-20 is beneficial for reducing inflammatory responses and ameliorating renal dysfunction in vivo.

\section{Higher serum IL-20 in diabetic patients with kidney dysfunction}

To further examine whether IL-20 was associated with diabetes mellitus (DM) and involved in the pathogenesis of DM, we 
a
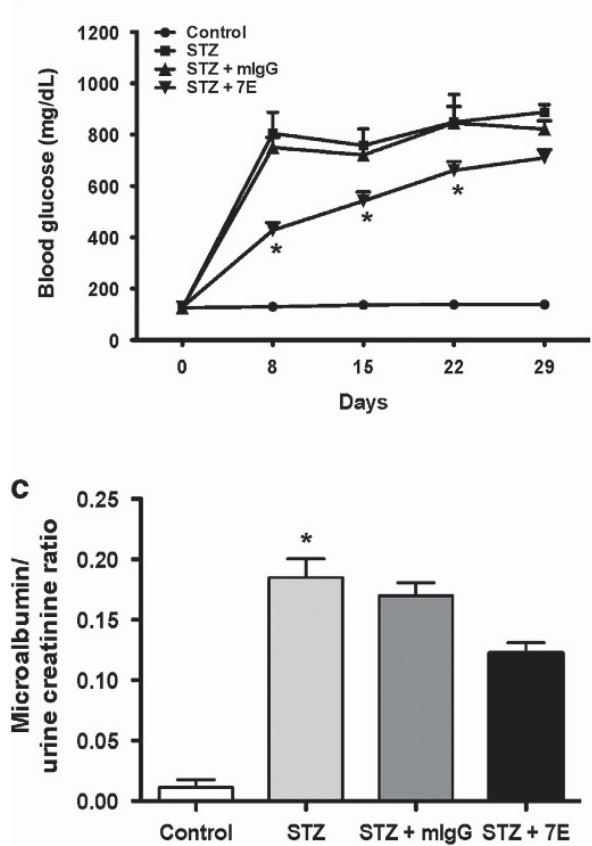

b

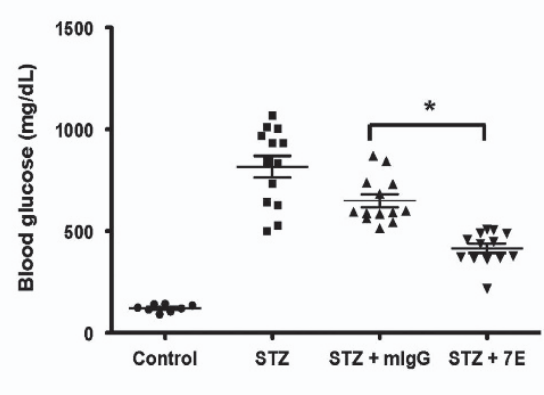

d

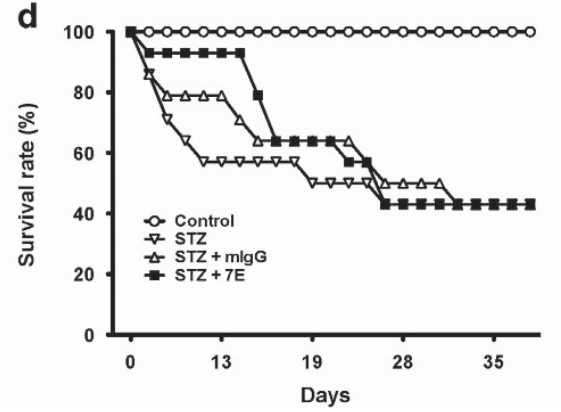

e

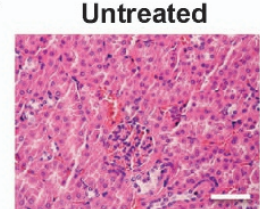

$\mathrm{STZ}+\mathrm{mlgG}$
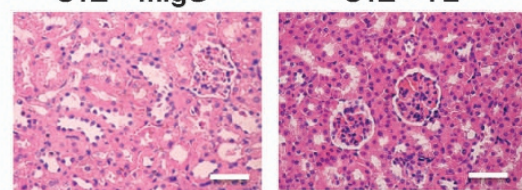

f

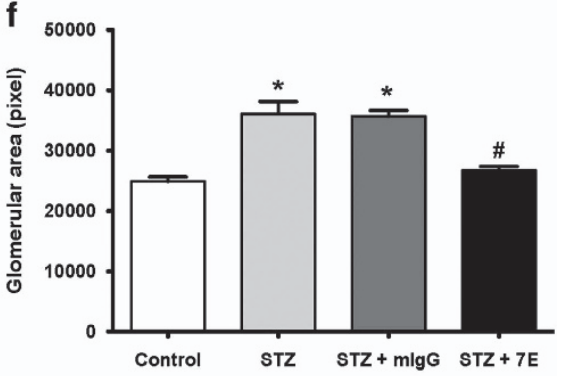

Figure 4 7E reduced the severity in high-dose STZ-induced early diabetic nephropathy. In the single high-dose STZ-injected model, the mice were divided into three groups: no treatment (STZ, $n=13), 3 \mathrm{mg} \mathrm{kg}^{-1} 7 \mathrm{E}(n=13)$ and $3 \mathrm{mg} \mathrm{kg}^{-1}$ control antibody (mlgG; $n=13$ ) twice per week until the end of the experiment. Control mice were injected with sodium citrate buffer alone. (a) Blood glucose was measured in each group from day 0 to 29 after STZ treatment. ${ }^{*} P<0.05$ compared with the mlgG controls. The data are expressed as the mean \pm s.e.m. and are representative of three independent experiments. (b) Blood glucose on day 8 was analyzed. ${ }^{*} P<0.05$ compared with the mlgG controls. The data are expressed as the mean \pm s.e.m. and are representative of three independent experiments. (c) The microalbumin/urine creatinine ratio was analyzed on day 21 after STZ treatment. ${ }^{*} P<0.05$ compared with the controls. The data are expressed as the mean \pm s.e.m. and are representative of three independent experiments. (d) Survival in mice treated with STZ $(n=13), \mathrm{STZ}+7 \mathrm{E}\left(3 \mathrm{mg} \mathrm{kg}^{-1}, n=13\right), \mathrm{STZ}+\mathrm{mlgG}\left(3 \mathrm{mg} \mathrm{kg}^{-1}, n=13\right)$ and control buffer $(n=8)$ was monitored daily until the end of the experiment. The data are representative of three independent experiments. (e) Kidney sections from each group were stained with hematoxylin and eosin. The data are representative of three independent experiments. Magnification: $\times 200$. Scale bars, $25 \mu \mathrm{m}$. (f) Glomerular areas in each group on day 21 were analyzed. ${ }^{*} P<0.05$ compared with the mlgG controls. The data are expressed as the mean \pm s.e.m. and are representative of three independent experiments.

analyzed the IL-20 serum levels in patients with DM and compared them with those of healthy controls. Forty-six healthy controls and 78 patients with DM were included in the analysis. The serum IL-20 concentration in DM patients was significantly higher than that in healthy controls $(P=0.0027)$. The median and mean values of IL-20 were 13.42 and $59.70 \mathrm{pg} \mathrm{ml}^{-1}$ in healthy controls, and 76.11 and $309.80 \mathrm{pg} \mathrm{ml}^{-1}$ in patients with diabetes mellitus, respectively (Figure 6a). A decreasing glomerular filtration rate (GFR) is a valuable indicator of the progression of diabetic nephropathy. To further analyze the association between IL-20 and DM patients with kidney dysfunction, 78 patients with DM were divided into four groups according to their GFR (DM-group 1, GFR $>100, n=27$; DM-group 2, GFR 90100, $n=6$; DM-group 3, GFR 60-89, $n=30$; DM-group 4, GFR $<60, n=15)$. The serum IL-20 level was significantly higher in DM-group 2 and DM-group 3 than in healthy controls (Figure 6b). The mean levels of IL-20 were $59.70,137.51,692.15,392.43$ and $301.70 \mathrm{pg} \mathrm{ml}^{-1}$ in healthy volunteers, DM-group 1, DM-group 2, DM-group 3 and DM-group 4, respectively.

\section{DISCUSSION}

In the present study, we found that IL-20 was upregulated on podocytes in the kidneys of mice and rats with STZ-induced diabetes. Podocytes, which endogenously express IL-20 receptors, were the target cells of IL-20. Hydrogen peroxide, high-dose glucose and TGF- $\beta 1$ induced the expression of IL-20 in podocytes. IL-20 induced podocyte apoptosis through the caspase-8-dependent pathway. In vivo, anti-IL-20 $\mathrm{mAb}$ reduced renal damage in STZ-induced early diabetic nephropathy. Renal function was improved and the survival rate was higher in IL-20R1-deficient mice than in wild-type mice with STZ-induced early diabetic nephropathy, which indicated that the IL-20/IL-20R1 axis is important for mediating inflammatory responses during the progression of diabetic nephropathy.

Proinflammatory cytokine levels are associated with the risk for developing diabetes. Recent studies ${ }^{26}$ have reported 

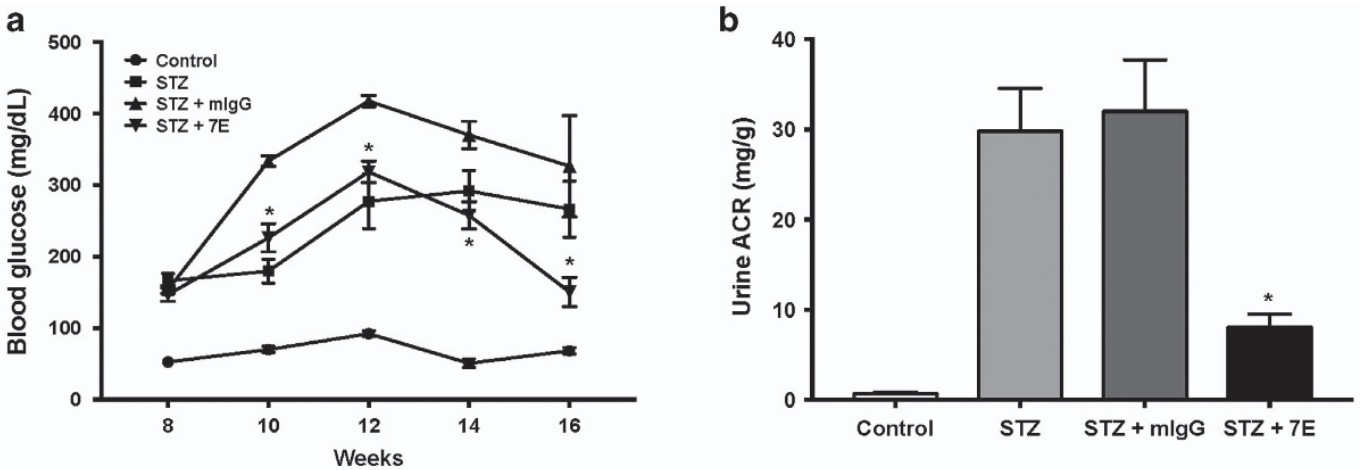

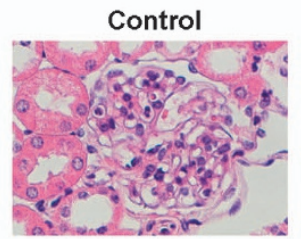

$\mathrm{STZ}+\mathrm{mlgG}$

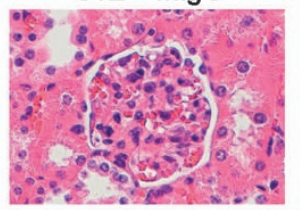

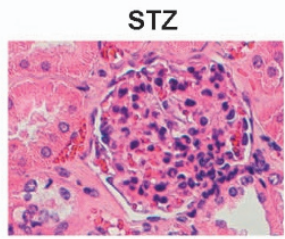

$\mathrm{STZ}+7 \mathrm{E}$

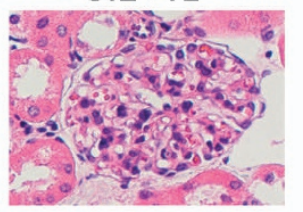

d

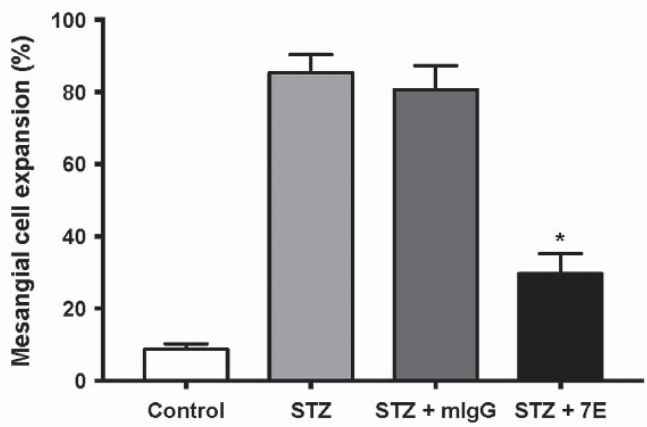

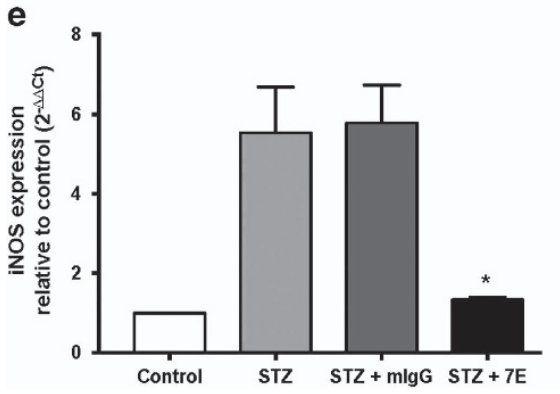


Figure 5 7E ameliorated the renal dysfunction in multiple low-dose STZ-induced diabetic nephropathy. In the multiple low-dose STZ-injected model, the mice were divided into three groups: no treatment (STZ, $n=9), 3 \mathrm{mg} \mathrm{kg}^{-1} 7 \mathrm{E}$ ( $n=9$ ), and $3 \mathrm{mg} \mathrm{kg}-1$ control antibody (mlgG) $(n=9)$ administered twice per week for 16 weeks. Control mice were injected with sodium citrate buffer alone. (a) Blood glucose was analyzed from weeks 8 to 16 after antibody treatment. ${ }^{*} P<0.05$ compared with the mlgG controls. The data are expressed as the mean \pm s.e.m. and are representative of three independent experiments. (b) The urine albumin/urine creatinine ratio (ACR) was analyzed 16 weeks after antibody treatment. ${ }^{*} P<0.05$ compared with the controls. The data are expressed as the mean \pm s.e.m. and are representative of three independent experiments. (c) Kidney sections from each group were stained with hematoxylin and eosin. The data are representative of three independent experiments. Magnification: $\times 200$. Scale bars, $25 \mu \mathrm{m}$. (d) The percentage of mesangial cell expansion in each group was analyzed. ${ }^{*} P<0.05$ compared with the mlgG controls. The data are expressed as the mean \pm s.e.m. $(\mathbf{e}-\mathbf{g})$ Renal tissues from control mice and STZ-induced diabetic nephropathy mice were collected, mRNA was isolated, and the transcripts of iNOS, TNF- $\alpha$, and MCP- 1 were measured by RT-qPCR. GAPDH served as an internal control. ${ }^{*} P<0.05$ compared with the $\mathrm{mlgG}$ controls. The data are expressed as the mean \pm s.d. of three independent experiments, each performed in triplicate.

that elevated circulating levels of TNF receptors 1 and 2 are strong, independent predictors of subsequent kidney function loss. IL-20 was upregulated in mice and rats with STZ-induced diabetes and in DM patients with kidney dysfunction. Therefore, whether IL-20 is a biomarker for predicting early diabetic nephropathy requires additional investigation.

Glucose-induced ROS cause apoptosis and the depletion of podocytes at the onset of diabetic nephropathy. ${ }^{7}$ Podocytes express CD80 (B7.1) in response to LPS and other types of stress. ${ }^{27} \mathrm{~A}$ recent study has reported that high-dose glucose induces podocyte B7.1 expression, thereby contributing to podocyte morphologic alternations and ultimately to diabetic nephropathy. ${ }^{28}$ We found that hydrogen peroxide and high-dose glucose upregulated IL-20 expression and that IL-20 caused apoptosis in podocytes. Therefore, ROS and highdose glucose may induce IL-20 upstream and result in 
a

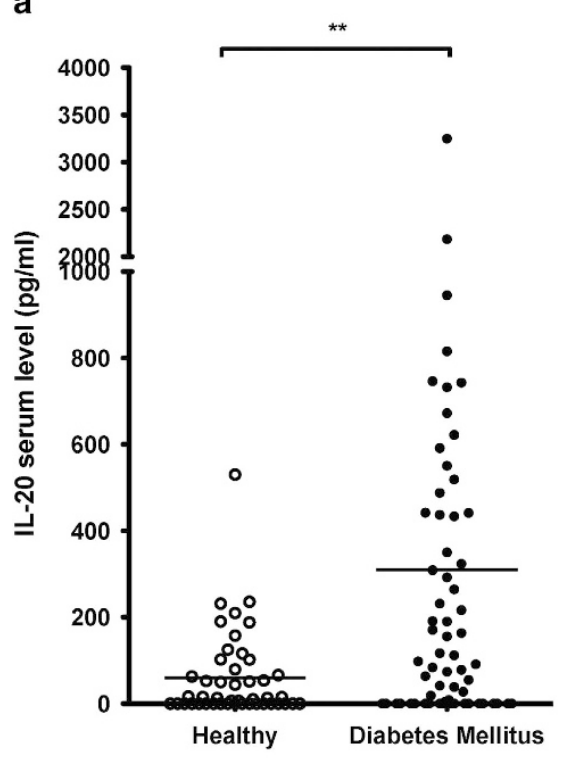



Figure 6 IL-20 was upregulated in the serum of patients with DM. (a) The serum levels of IL-20 were analyzed in 46 healthy volunteers and 78 patients with DM. The mean levels of IL-20 were $59.70 \mathrm{pg} \mathrm{ml}^{-1}$ in healthy volunteers, and $309.80 \mathrm{pg} \mathrm{ml}^{-1}$ in DM patients. The lines inside the boxes represent the mean IL-20 values. ${ }^{*} P<0.01$ compared with healthy controls. The data are representative of three independent experiments. (b) To analyze the association between IL-20 and DM patients with kidney dysfunction, 78 patients with DM were divided into four groups according to the GFR (DM-group 1, GFR>100, $n=27$; DM-group 2, GFR 90-100, $n=6$; DM-group 3, GFR 60-89, $n=30$; DM-group 4, GFR $<60, n=15)$. The mean levels of IL-20 were 59.70, 137.51, 692.15, 392.43 and $301.70 \mathrm{pg} \mathrm{ml}^{-1}$ in healthy volunteers, DM-group 1, DM-group 2, DM-group 3 and DM-group 4, respectively. The lines inside the boxes represent the mean IL-20 values. ${ }^{*} P<0.05,{ }^{*} P<0.01$ compared with the healthy controls. The data are representative of three independent experiments.

an amplification loop that causes apoptosis in podocytes. Additional studies are needed to clarify whether IL-20 plays a role in high-dose glucose-induced B7.1 expression in podocytes. Moreover, we have previously demonstrated ${ }^{29}$ that IL-20 induced ROS production in mesangial cells. This finding suggested that IL-20 might cause podocyte apoptosis directly or indirectly by triggering mesangial cells to produce ROS in the microenvironment of the glomerulus.

TGF- $\beta 1$ is a key player in the pathogenesis of diabetic nephropathy. ${ }^{3}$ Growing evidence suggests that podocytederived VEGF and other angiogenic or permeability factors, such as MMP-9 and MCP-1, increase the macromolecular permeability of the glomerular capillaries by affecting blood flow and glomerular endothelial cell function. ${ }^{30-32}$ We found that IL-20 stimulated podocytes to produce TGF- $\beta 1$, VEGF, MCP-1 and MMP-9, implying that IL-20 is involved in the progression of diabetic nephropathy and may also contribute to the cascade of inflammation and diabetic glomerulopathy.

IL-20 activated ERK, JNK and p38 in mouse podocytes. Both the p38 and JNK pathways are activated in human renal disease, including glomerulonephritis, diabetic nephropathy and acute renal failure. In addition, high-dose glucoseinduced VEGF and MMP-9 expression in podocytes is mediated through the ERK pathway. ${ }^{33,34}$ More evidence is needed to confirm that IL-20 induces cell death by activating
JNK and p38 and that it induces VEGF and MMP-9 by activating ERK.

IL-20R1 was upregulated in the kidneys of STZ-treated mice. IL-20R1-deficient mice showed lower levels of serum BUN than wild-type controls, indicating improved kidney function. Although we were unable to verify that the protective effect was attributable to the systemic or local absence of IL-20 signaling in this model, we showed that IL-20R1deficienct mice had a protective phenotype in our model of early stage diabetic nephropathy.

STZ has an acute toxic effect on multiple organs, and it is possible that STZ toxicity rather than complications of diabetes contributed to the deaths in the animal model. ${ }^{35}$ In the present study, we used high-dose STZ to induce diabetes in both rats and mice. Our in vivo data showed that an IL-20R1-deficiency and 7E treatment improved the survival rate of mice in the early stage but not in the late stage of diabetic neuropathy. Moreover, we also found that a deficiency in IL-20R1 and 7E treatment reduced the degree of hyperglycemia in our animal model. This phenomenon raised the possibility that IL-20 inhibition may not only improve kidney function but also reduce the tissue damage in other vital organs. Furthermore, whether IL-20 plays a role in the regulation of blood glucose awaits future investigation. 
We demonstrated an upregulation of the serum level of IL-20 in patients with DM. The level of IL-20 was significantly increased in diabetic patients with kidney dysfunction. These data suggest that IL-20 is a proinflammatory cytokine that participates in the pathogenesis of diabetic nephropathy. They also indicated that IL-20 is not only expressed in local tissues (kidney) but also in the systemic circulation. In addition to kidney tissue, DM also damages other organs such as the heart, eyes and brain. Further analyses are needed to investigate whether circulating IL-20 injures other organs in DM.

In conclusion, our study revealed that IL-20 is an inflammatory mediator that participates in the early stage of diabetic nephropathy. IL-20 was upregulated in mice and rats with STZ-induced diabetes and in DM patients with kidney dysfunction. In vitro, IL-20 targeted podocytes and induced cellular apoptosis and fibrotic gene expression. IL-20 expression was upregulated by ROS, glucose, and TGF- $\beta 1$. In vivo, IL-20R1deficient mice showed improved renal function and less severe diabetic nephropathy compared with mice expressing IL-20R1. Collectively, our findings provide evidence that IL-20 targets podocytes and is involved in the pathogenesis of early stage diabetic nephropathy.

\section{CONFLICT OF INTEREST}

The authors declare no conflict of interest.

\section{ACKNOWLEDGEMENTS}

This work was supported by the Ministry of Science and Technology of Taiwan (NSC 102-2311-B-006-001, and NSC 103-2311-B-006-002, and 104-2311-B-006-007-MY2).

Author contributions: M-SC conceived and supervised the study. $\mathrm{M}-\mathrm{SC}, \mathrm{Y}-\mathrm{HH}$ and $\mathrm{H}-\mathrm{HL}$ designed the experiments, interpreted the results and generated the figures. J-MS and C-HW collected the clinical samples and analyzed the data. Y-HH, H-HL and W-YC, wrote the manuscript. Y-HH, H-HL, Y-CH, Y-HW and W-TL performed the experiments and analyzed the data. All authors discussed the data and commented on the manuscript before submission.

1 Fioretto P, Steffes MW, Brown DM, Mauer SM. An overview of renal pathology in insulin-dependent diabetes mellitus in relationship to altered glomerular hemodynamics. Am J Kidney Dis 1992; 20: 549-558.

2 Mauer M, Drummond K. The early natural history of nephropathy in type 1 diabetes: I. Study design and baseline characteristics of the study participants. Diabetes 2002; 51: 1572-1579.

3 Ziyadeh FN. Mediators of diabetic renal disease: the case for tgf-Beta as the major mediator. J Am Soc Nephrol 2004; 15(Suppl 1): S55-S57.

4 Ziyadeh FN, Sharma K. Overview: combating diabetic nephropathy. J Am Soc Nephrol 2003; 14: 1355-1357.

5 Petermann AT, Krofft R, Blonski M, Hiromura K, Vaughn M, Pichler R et al. Podocytes that detach in experimental membranous nephropathy are viable. Kidney Int 2003; 64: 1222-1231.

6 Bottinger EP, Bitzer M. TGF-beta signaling in renal disease. J Am Soc Nephrol 2002; 13: 2600-2610.

7 Susztak K, Raff AC, Schiffer M, Bottinger EP. Glucose-induced reactive oxygen species cause apoptosis of podocytes and podocyte depletion at the onset of diabetic nephropathy. Diabetes 2006; 55 : 225-233.

8 Blumberg H, Conklin D, Xu WF, Grossmann A, Brender T, Carollo S et al. Interleukin 20: discovery, receptor identification, and role in epidermal function. Cell 2001; 104: 9-19.

9 Pestka S, Krause CD, Sarkar D, Walter MR, Shi Y, Fisher PB. Interleukin-10 and related cytokines and receptors. Annu Rev Immunol 2004; 22: 929-979.

10 Dumoutier L, Leemans C, Lejeune D, Kotenko SV, Renauld JC. Cutting edge: STAT activation by IL-19, IL-20 and mda-7 through IL-20 receptor complexes of two types. J Immunol 2001; 167: 3545-3549.

11 Hsieh MY, Chen WY, Jiang MJ, Cheng BC, Huang TY, Chang MS. Interleukin-20 promotes angiogenesis in a direct and indirect manner. Genes Immun 2006; 7: 234-242.

$12 \mathrm{Hsu}$ YH, Li HH, Hsieh MY, Liu MF, Huang KY, Chin LS et al. Function of interleukin-20 as a proinflammatory molecule in rheumatoid and experimental arthritis. Arthritis Rheum 2006; 54: 2722-2733.

$13 \mathrm{Li} \mathrm{HH}$, Hsu YH, Wei CC, Lee PT, Chen WC, Chang MS. Interleukin-20 induced cell death in renal epithelial cells and was associated with acute renal failure. Genes Immun 2008; 9: 395-404.

$14 \mathrm{Hsu} \mathrm{YH}$, Hsing $\mathrm{CH}$, Li CF, Chan $\mathrm{CH}$, Chang MC, Yan JJ et al. Anti-IL-20 monoclonal antibody suppresses breast cancer progression and bone osteolysis in murine models. J Immunol 2012; 188: 1981-1991.

15 Hsu YH, Wei CC, Shieh DB, Chan CH, Chang MS. Anti-IL-20 monoclonal antibody alleviates inflammation in oral cancer and suppresses tumor growth. Mol Cancer Res 2012; 10: 1430-1439.

16 Wei CC, Hsu YH, Li HH, Wang YC, Hsieh MY, Chen WY et al. IL-20: biological functions and clinical implications. J Biomed Sci 2006; 13: 601-612.

17 Sa SM, Valdez PA, Wu J, Jung K, Zhong F, Hall L et al. The effects of IL-20 subfamily cytokines on reconstituted human epidermis suggest potential roles in cutaneous innate defense and pathogenic adaptive immunity in psoriasis. J Immunol 2007; 178: 2229-2240.

18 Wei CC, Chen WY, Wang YC, Chen PJ, Lee JY, Wong TW et al. Detection of IL-20 and its receptors on psoriatic skin. Clin Immunol 2005; 117: $65-72$.

19 Caligiuri G, Kaveri SV, Nicoletti A. IL-20 and atherosclerosis: another brick in the wall. Arterioscler Thromb Vasc Biol 2006; 26: 1929-1930.

20 Chen WY, Chang MS. IL-20 is regulated by hypoxia-inducible factor and up-regulated after experimental ischemic stroke. J Immunol 2009; 182: 5003-5012.

21 Wei CC, Li HH, Hsu YH, Hsing CH, Sung JM, Chang MS. Interleukin-20 targets renal cells and is associated with chronic kidney disease. Biochem Biophys Res Commun 2008; 374: 448-453.

22 Rossini AA, Like AA, Chick WL, Appel MC, Cahill GF Jr. Studies of streptozotocin-induced insulitis and diabetes. Proc Natl Acad Sci USA 1977; 74: 2485-2489.

23 Mundel P, Reiser J, Zuniga Mejia Borja A, Pavenstadt H, Davidson GR, Kriz W et al. Rearrangements of the cytoskeleton and cell contacts induce process formation during differentiation of conditionally immortalized mouse podocyte cell lines. Exp Cell Res 1997; 236: 248-258.

24 Rangan GK, Tesch GH. Quantification of renal pathology by image analysis. Nephrology 2007; 12: 553-558.

25 Brosius FC 3rd. New insights into the mechanisms of fibrosis and sclerosis in diabetic nephropathy. Rev Endocr Metab Dis 2008; 9: 245-254.

26 Niewczas MA, Gohda T, Skupien J, Smiles AM, Walker WH, Rosetti F et al. Circulating TNF receptors 1 and 2 predict ESRD in type 2 diabetes. $J$ Am Soc Nephrol 2012; 23: 507-515.

27 Reiser J, von Gersdorff G, Loos M, Oh J, Asanuma K, Giardino L et al. Induction of B7-1 in podocytes is associated with nephrotic syndrome. J Clin Invest 2004; 113: 1390-1397.

28 Fiorina P, Vergani A, Bassi R, Niewczas MA, Altintas MM, Pezzolesi MG et al. Role of podocyte B7-1 in diabetic nephropathy. J Am Soc Nephrol 2014; 25: 1415-1429.

$29 \mathrm{Li} \mathrm{HH}$, Cheng HH, Sun KH, Wei CC, Li CF, Chen WC et al. Interleukin-20 targets renal mesangial cells and is associated with lupus nephritis. Clin Immunol 2008; 129: 277-285.

30 de Vriese AS, Tilton RG, Elger M, Stephan CC, Kriz W, Lameire NH. Antibodies against vascular endothelial growth factor improve early 
renal dysfunction in experimental diabetes. J Am Soc Nephrol 2001; 12: 993-1000.

31 Sung SH, Ziyadeh FN, Wang A, Pyagay PE, Kanwar YS, Chen S. Blockade of vascular endothelial growth factor signaling ameliorates diabetic albuminuria in mice. J Am Soc Nephrol 2006; 17: 3093-3104.

32 Lee EY, Chung $\mathrm{CH}$, Khoury CC, Yeo TK, Pyagay PE, Wang A et al. The monocyte chemoattractant protein-1/CCR2 loop, inducible by TGF-beta, increases podocyte motility and albumin permeability. Am J Physiol Renal Physiol 2009; 297: F85-F94.

33 Hoshi S, Nomoto K, Kuromitsu J, Tomari S, Nagata M. High glucose induced VEGF expression via PKC and ERK in glomerular podocytes. Biochem Biophys Res Commun 2002; 290: 177-184.

34 Bai YL, Huang HC, Li JZ, Zhao YY, Wang HY. [High glucose regulates the production of MMP-9 in podocyte through ERK1/2 signal pathway]. Zhonghua yi xue za zhi 2005; 85: 1451-1455.
35 Deeds MC, Anderson JM, Armstrong AS, Gastineau DA, Hiddinga HJ, Jahangir A et al. Single dose streptozotocin-induced diabetes: considerations for study design in islet transplantation models. Lab Anim 2011; 45: 131-140.

cc) (i) (2) $\odot$ This work is licensed under a Creative Commons Attribution-NonCommercial-NoDerivs 4.0 International License. The images or other third party material in this article are included in the article's Creative Commons license, unless indicated otherwise in the credit line; if the material is not included under the Creative Commons license, users will need to obtain permission from the license holder to reproduce the material. To view a copy of this license, visit http://creativecommons.org/licenses/by-nc-nd/4.0/

Supplementary Information accompanies the paper on Experimental \& Molecular Medicine website (http://www.nature.com/emm) 